\title{
Journal of Information Science
}

http://jis.sagepub.com/

\section{Can organizational knowledge capabilities affect knowledge sharing behavior? \\ Chyan Yang and Liang-Chu Chen \\ Journal of Information Science 2007 33: 95 \\ DOI: $10.1177 / 0165551506068135$}

The online version of this article can be found at:

http://jis.sagepub.com/content/33/1/95

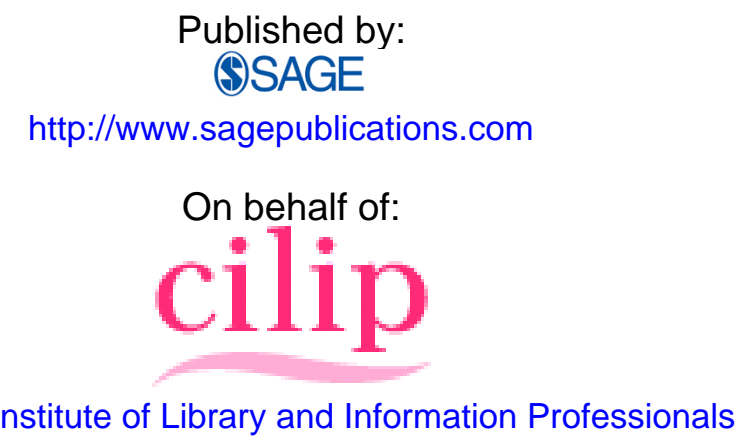

Additional services and information for Journal of Information Science can be found at:

Email Alerts: http://jis.sagepub.com/cgi/alerts

Subscriptions: http://jis.sagepub.com/subscriptions

Reprints: http://www.sagepub.com/journalsReprints.nav

Permissions: http://www.sagepub.com/journalsPermissions.nav

Citations: http://jis.sagepub.com/content/33/1/95.refs.html

>> Version of Record - Feb 6, 2007

What is This? 


\title{
Can organizational knowledge capabilities affect knowledge sharing behavior?
}

\author{
Chyan Yang \\ Institute of Business and Management and Institute of Information Management, \\ National Chiao Tung University, Taiwan

\section{Liang-Chu Chen} \\ Department of Information Management, Management College, National Defense University, Taiwan
}

Received 3 August 2005

Revised 17 November 2005

\begin{abstract}
.
Recent concerns about the issue of knowledge management (KM) within an organization have accentuated the need for more efficient and effective knowledge sharing - that is, knowledge sharing plays an increasingly significant role in determining the outcomes of KM. Most scholars explore this issue from the economic perspective, while only a few research studies have focussed on organizational capabilities. Drawing from the theories of resource-based view and KM, this study aims to investigate the relationship between organizational knowledge capabilities (OKC) and knowledge sharing (KS). Using regression analysis with data from questionnaires collected in different industries with a valid response rate of $62.4 \%$, the results show that OKC have a positive association with KS. Technical, structural, and human knowledge capabilities are significant for organizational knowledge sharing. Moreover, the effects of implementing KM on OKC and KS are also significant.
\end{abstract}

Keywords: knowledge management; knowledge sharing; organizational knowledge capability

\section{Introduction}

In the literature concerning knowledge management (KM) within an organization, most researchers acknowledge the important role knowledge sharing Plays in the development of KM [1-3] and business success [4, 5], but also that it is difficult work [6, 7]. Several factors have been proposed as driving the behavior of knowledge sharing, such as a participant's motivation, social relationship, and organizational culture [7-9]. Moreover, Shin [1] constructed an integrated knowledge sharing 
framework to identify the important variables and relationships from economic perspectives. Cummings and Teng [10] empirically tested the key factors affecting R\&D knowledge sharing from a context viewpoint. Alavi and Leidner [11] proposed some research suggestions for effective knowledge sharing from the organizational perspective, including the social, cultural, and technical attributes. Some scholars attempted to explain knowledge sharing using an intention-behavior perspective [12-14]. However, few research studies focus on the area of capabilities.

The purpose of this study is to examine the ways in which different organizational knowledge capabilities can improve organizational resources for effective knowledge sharing. The relationship between knowledge sharing (KS) and organizational knowledge capabilities (OKC) is developed and analyzed herein.

The paper is organized as follows. In the first section we discuss the two core concepts - namely, knowledge sharing and organizational knowledge capabilities. The next section proposes a research model and explains the relationship between different variables. This is followed by a section in which we introduce the research methodology and analyze the results. Finally, we discuss the implications and conclusions.

\section{Literature review}

\subsection{Knowledge sharing}

To successfully achieve effectiveness in knowledge management, knowledge sharing should be the most important consideration [1, 2]. Many organizations already achieve significant benefits through knowledge sharing activities, e.g. Toyota [15], Texas Instruments (TI), Dow Chemical [1, 4], and Ford [16].

Knowledge sharing is depicted as a set of behaviors about knowledge exchange which involve the actors, knowledge content, organizational context, appropriate media, and societal environment $[1,17,18]$. Hendriks [3] suggested a conceptualized model which consists of two main activities for effective knowledge sharing: transmission and absorption [7, 17]. The knowledge owner externalizes his knowledge through the skills of codification, elaboration, and presentation. Knowledge is subsequently transmitted to the recipient (reconstructor) by the appropriate media or channels, and then the reconstructor internalizes this knowledge through the capabilities of reading, learning, interpreting, and absorbing. Therefore, knowledge sharing involves many complicated and varying factors and research is needed to identify what factors help foster knowledge sharing.

Lee [19] proposed two types of knowledge: explicit knowledge, which can be clearly articulated in written documents (e.g. business reports), and implicit knowledge, which is embedded into an individual's experience (e.g. know-how). Bock et al. [12] integrated the organizational climate construct and TRA (theory of reasoned action) model, which consists of the attitude of knowledge sharing and subjective norm, in order to demonstrate why knowledge workers participate in knowledge sharing behavior. Ryu et al. [13] measured knowledge sharing behavior by combining aspects of TRA and TPB (theory of planned behavior). Lee and Suliman [18] proposed a knowledge sharing framework which is affected by five factors - the actors who participate in the activity, the characteristics of the shared knowledge, the organizational concerns, the channel which is used to communicate with others, and the environmental climate. Ruggles [20] found that the important impediments for knowledge sharing include culture (54\%), organizational structure (28\%), information communication technology (22\%), incentive system (19\%), and staff turnover (8\%), by investigating 431 US and European organizations.

To explore multiple factors impacting knowledge sharing, we categorize these factors into three dimensions based on Lee and Suliman [18] and four sub-dimensions at the organizational level based on the socio-technical view [21,22] (see Table 1). The socio-technical view is a method of considering the organizational interrelatedness of the social and technological subsystems [22]. Normally, the technical dimension is based on IT infrastructure and the social dimension emphasizes the importance of culture, structure, people, task, and environment. 
Yang \& Chen: Organizational knowledge capabilities

Table 1

Summary of knowledge sharing factors

\begin{tabular}{llll}
\hline Dimension & Sub-dimension & Factors & References \\
\hline Organizational level & Culture & $\begin{array}{l}\text { Sharing culture/Cooperation and collaboration culture/ } \\
\text { Knowledge-centered culture/Learning culture }\end{array}$ & {$[10,18,23-27]$} \\
& Structure & $\begin{array}{l}\text { Incentive and reward/Work design/Management } \\
\text { support/Norm/Political directives }\end{array}$ & {$[12,18,23-25,27,28]$} \\
& People & Arduous relationship/Shared understanding/ & {$[8,10,25,29,30]$} \\
& Sechnology & IT infrastructure/IT know-how/IT support & {$[3,18,24,31,32]$} \\
& & Motivation/Prior experience/Absorptive & {$[3,8,17,18,23,29]$} \\
Individual level & & capacity/Source credibility & {$[8,10,18,23-25]$} \\
& & Explicit and tacit knowledge/Causal ambiguity/ & \\
Knowledge level & & Knowledge articulability/Knowledge embeddedness & \\
\hline
\end{tabular}

However, this study examines capabilities from the perspective of organizational knowledge, and the need to foster the creation, acquirement, integration, and dissimilation of organizational knowledge, rather than from an individual's viewpoint. For example, prior experience embedded in an individual is hard for an organization to create. On the other hand, the characteristics of knowledge level involve the original knowledge presentation and meanings, which are not the purpose of this study. For example, causal ambiguity of knowledge cannot be made clearer by organizational dissimilation. Therefore, we adopt the first dimension, which is composed of culture, structure, people, and technology, as the important factor in organizational knowledge sharing. The remaining two dimensions, individual and knowledge level, are ignored herein.

\subsection{Organizational knowledge capabilities}

What are knowledge capabilities for an organization? Gorman and Thomas stressed that 'capabilities are somewhat less tangible and less visible process-oriented resources' [33, p. 615]. Dutta et al. [34] claimed that capabilities refer to how a firm deploys resources for generating value and achieving organizational objectives. The issues of organizational capabilities as the outcome of knowledge integration have recently been explored using the theories of resource-based view (RBV) and knowledge-based view (KBV) [35, 36] - that is, knowledge can be found in individuals and capabilities should be developed to integrate such knowledge within an organization. Moreover, organizational knowledge capabilities (OKC) are developed to perform knowledge processes (generating, capturing, sharing, and applying) more effectively so as to achieve organizational success [37]. To develop OKC successfully, two primary means (technology, and skills and behaviors) were proposed by Dawson [37] which are consistent with the socio-technical perspective [22, 38].

Knowledge management capability (KMC) represents the ability to mobilize and deploy knowledge resources in combination with other resources and capabilities for enabling KM activities, and it has a positive effect on competitive advantage [39] and organizational effectiveness [36]. Successful KM has to connect many organizational components, including technology, human resource practices, organizational structure, and culture, to ensure that the right knowledge is brought to the right people [40] and to facilitate KM initiatives [36]. Chuang's [39] research also adopted the socio-technical viewpoint to classify KM resources into two types; social and technical knowledge resources. In summary, OKC and KMC have similar meanings and contexts. We will treat the two terms as the same concept and use OKC as the research variable in this study. Therefore, four types of OKC (cultural, structural, human, and technical knowledge capability), based on the perspective of Chuang [39] and Gold et al. [36], are examined in this study. 
Yang \& Chen: Organizational knowledge capabilities

\section{Theories and hypotheses}

To explore the factors affecting knowledge sharing activities from the organizational perspective, four organizational resources (culture, structure, people, and technology) are proposed in Section 2. Drawing from the theories of RBV and KBV, capabilities are clearly noted as 'intermediate transformation ability' between resources and objectives [34]. Therefore, this study adopts the viewpoint of knowledge capabilities for operating organizational resources more effectively. A framework (shown in Figure 1) is proposed to test the relationship between organizational knowledge capabilities and knowledge sharing behaviors.

This framework presents KS as a dependent variable and OKC as independent variables. KS covers the actual activities in the exchange of explicit or implicit knowledge [12, 19]. OKC consists of four domains: cultural, structural, human, and technical knowledge capabilities [36, 39], which emphasize the ability to mobilize and deploy knowledge resources more effectively. Moreover, the implementation of KM as a comparative condition to test the effects on OKC and KS is also examined. Accordingly, this study sets forth seven hypotheses and assesses them empirically.

\subsection{Organizational knowledge capability and knowledge sharing}

The core capabilities of knowledge organization are important in providing information and knowledge-based services. Wiig [41] claimed that KM initiatives will fail if the investments of organizational resources and capabilities are inappropriate. In other words, effective KM should contribute to organizational performance through the development of organizational knowledge capability [36]. Lee's [19] empirical research revealed that an organizational capability to learn or acquire the needed knowledge from other organizations is a key resource for successful knowledge sharing. Thus, the enhancement of knowledge capabilities as the foundation of organizational development is beneficial for organizational effectiveness. Normally, organizational capabilities invest on process improvement, work effectiveness, learning, and supporting technology that facilitate knowledge

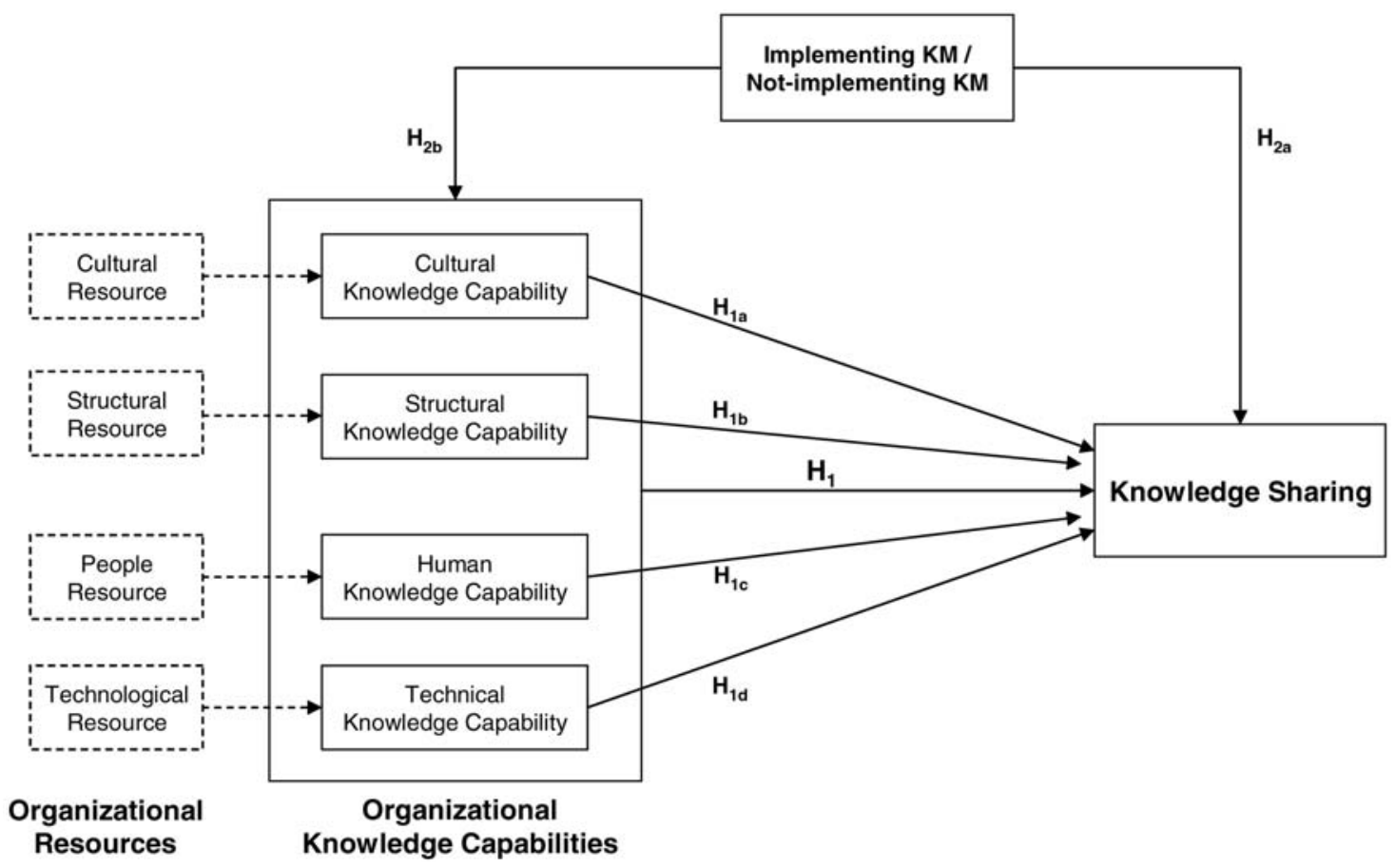

Fig. 1. A framework linking organizational knowledge capabilities to knowledge sharing. 
Yang \& Chen: Organizational knowledge capabilities

transfer and sharing. Hence, these are needed if a firm strengthening OKC hopes to see the effectiveness and efficiency of knowledge sharing. Therefore, we propose:

Hypothesis 1: Organizational knowledge capabilities have a positive effect on the knowledge sharing behavior within an organization.

3.1.1. Cultural knowledge capability and sharing Organizational culture is the most frequentlycited factor supporting knowledge sharing [16, 25]. De Long and Fahey [42] identified four different ways in which culture influences the behaviors central to KM activities (creation, sharing, and use). Cummings and Teng [10] stressed that learning culture affects knowledge sharing, which focuses on the recipient context. Goh [25] proposed that cooperative and collaborative culture is an important prerequisite to drive a propensity for high knowledge sharing. Janz and Prasarnphanich [26] revealed that knowledge-centered culture is an effective factor for cooperative learning. Thus, the effectiveness of organizational culture is one of the critical capabilities influencing a firm's survival and success [43]. Therefore, we propose:

Hypothesis 1a: Cultural knowledge capabilities have a positive effect on the knowledge sharing behavior with in an organization.

3.1.2. Structural knowledge capability and sharing Organizational structure is frequently mentioned as the solution to intra-organizational knowledge sharing issues [25, 44]. Normally, two structural factors are presented in organizational activities. First, an appropriate incentive and reward mechanism enhances the motivation to share knowledge [7, 28]. For example, Hall [28] divided the rewards for knowledge sharing into hard and soft rewards. The former consists of economic pay, learning opportunities, and career advancement, and the latter includes enhanced reputation and personal satisfaction. Second, political directives are effective forces for inspiring employees' motivation to share knowledge [24]. Therefore, we propose:

Hypothesis 1b: Structural knowledge capabilities have a positive effect on the knowledge sharing behavior within an organization.

3.1.3. Human knowledge capability and sharing Teams, relationships, and networks are the most important elements in transfering and sharing knowledge effectively [4]. Szulanski [8] and Ko et al. [29] proved empirically that an arduous relationship is a significant barrier to the occurrence of knowledge sharing. Tsai [30] suggested that social interaction has a positive correlation with intra-organizational knowledge sharing. As noted by Yang and Wan [43], social interactions can be an efficient method of transferring tacit knowledge. Thus, working closely with others and having a familiarity between the source and recipient in an organization are important antecedents of knowledge sharing, through shared understanding [29].

Human knowledge capability is conceptualized herein as having two important aspects. First, the relationship between the knowledge owner and recipient must be appropriately constructed. Second, the degree of acquaintance and understanding among a firm's members is measured. Therefore, we propose:

Hypothesis 1c: Human knowledge capabilities have a positive effect on the knowledge sharing behavior within an organization.

3.1.4. Technical knowledge capability and sharing Information technology (IT) is a critical enabler when a business implements a KM program, as it has both direct and indirect influences on knowledge sharing $[3,18]$ by increasing the speed of sharing and by decreasing costs due to time and distance [45]. Bolisani and Scarso [31] studied different cases and found various information communication technologies (ICT) which are effective tools for knowledge sharing activities in an organization. ICT infrastructure and ICT know-how also have a significant effect on KS performance [24].

ICT is an infrastructure which supports the information platform for accessing and distributing knowledge. However, without capabilities for using ICT, the platform is worthless. To support 
Yang \& Chen: Organizational knowledge capabilities

knowledge activities, IT may reasonably be viewed as an organizational capability [46] and various capabilities for holding, deploying, and accessing knowledge are required at different stages of the KM initiatives [41]. Therefore, we propose:

Hypothesis 1d: Technical knowledge capabilities have a positive effect on the knowledge sharing behaviors in an organization.

\section{2. $K M, O K C$, and $K S$}

In KM studies the perspectives of the KBV and organizational capabilities are primary themes [47]. KBV emphasizes the importance of organizational knowledge which leads to organizational advantage and business success [12,33], while organizational capability focuses on deploying resources effectively to improve the business process. Since organizational knowledge capabilities impact directly on successful KM [36, 48], the positive relationship could be confirmed. On the other hand, knowledge sharing is the most significant objective for effective KM [1-3]. Thus, when examining whether KM activities are successful, the effectiveness of knowledge sharing provides some appropriate evidence.

This study is primarily concerned with testing this question: does the implementation of KM contribute to organizational knowledge capabilities and knowledge sharing activities? Therefore, we propose:

Hypothesis 2a: Firms which implement KM will be more participative in knowledge sharing activities than firms which do not.

Hypothesis 2b: Firms which implement KM will be better in organizational knowledge capabilities (cultural, structural, technical, and human) than firms which do not.

\section{Research methodology}

\subsection{Data collection and sample description}

The sample was designed to include people from different positions, departments, and industries. Respondents included students from EMBA (executive rank managers of various organizations, average age around 43) and MBA (middle level managers, average age around 33) programs in Taiwan. The questionnaires' data are arranged in terms of the various variables, and seven-point Likert scales are used. Respondents are asked to indicate the extent to which they disagree or agree with the given statement by selecting a point on the scale for each question (where 1 = strongly disagree and 7 = strongly agree).

A two-stage pilot test was conducted before sending out the final questionnaire version. First, we invited 10 doctoral students from three institutes of the National Chiao Tung University (Taiwan) to examine the syntax of the questionnaires' items. Secondly, 10 company employees were asked to check the semantic content of the questionnaires.

The survey was conducted over a period of two months. We received 278 questionnaires from 410 questionnaires sent, giving a response rate of $67.8 \%$. However, 22 of these responses were not usable, yielding 256 effective questionnaires and a usable response rate of $62.4 \%$. The appendix (Table A1) summarizes the respondents' characteristics according to industry type and demographics.

\subsection{Survey instrument}

This research uses a survey questionnaire to test the hypotheses described in Section 3. The proposed model measures organizational knowledge capabilities using 15 items to describe the ability to deploy knowledge resources [36, 37, 39]. They include cultural knowledge capabilities (four items), structural knowledge capabilities (four items), human knowledge capabilities (three items), and technical knowledge capabilities (four items). Knowledge sharing is measured by seven items 
Yang \& Chen: Organizational knowledge capabilities

Table 2

Research variables

\begin{tabular}{lll}
\hline Variables & Definitions & Related literature \\
\hline Organizational knowledge capability & $\begin{array}{l}\text { The ability to mobilize and deploy knowledge resources } \\
\text { in combination with other resources and capabilities } \\
\text { in order to perform knowledge processes effectively. }\end{array}$ & {$[36,37,39]$} \\
Cultural knowledge capability & $\begin{array}{l}\text { The supportive capability for valuing organizational } \\
\text { knowledge and building up an interactive, collaborative } \\
\text { atmosphere among organizational members. }\end{array}$ & {$[21,36,39]$} \\
Structural knowledge capability & $\begin{array}{l}\text { The integrative capability such as norm, policy, context, } \\
\text { and an incentive system within an organization aims at } \\
\text { creating new knowledge. }\end{array}$ & {$[21,36,39]$} \\
Human knowledge capability & $\begin{array}{l}\text { The relationships and interpersonal understanding among } \\
\text { organizational members. }\end{array}$ & {$[21,36,39]$} \\
Technical knowledge capability & The ability to integrate and deploy knowledge by using & {$[21,36,39,46]$} \\
ICT effectively. & The degree to which organizational members actually & {$[12-14,19]$}
\end{tabular}

which focus on the activities of explicit and implicit knowledge sharing [12-14, 19]. Table 2 lists the definitions of the variables and the related literature, for confirmation of the validity of the content. In addition, three demographic characteristics [49] and one organizational attribute [30, 44] are used as control variables: gender, age, education, and firm size. All measured items are shown in the Appendix (Table A2) and the results were coded using SPSS for Windows.

\section{Analysis and results}

\subsection{Results of exploratory factor analysis}

To identify the dimensions of the organizational knowledge capabilities, we conduct a principal component analysis with varimax rotation from selected responses. Four factors are extracted and each item fits strongly with only one factor; however, the partial factors inconsistent with Chuang [39] and Gold et al. [36] are eliminated. The remaining 15 items assessed by the scale reliability are acceptable since the alpha values are all greater than 0.82, exceeding the cut-off value (0.7) (see Table 3).

The results account for nearly $72.2 \%$ of the cumulative variance. Among the four factors, technical knowledge capability (TKC) explains the largest portion (43.9\%) of the total variance, and so appears to be the most important factor. TKC is required to operate and deploy an information infrastructure effectively. The cultural knowledge capability (CKC) accounts for $15.4 \%$ of the total variance, and improves the interactive and collaborative atmosphere of an organization. The third factor, structural knowledge capability (SKC), accounts for $6.9 \%$ of the total variance, and consists of the political directives and reward mechanism. Lastly, human knowledge capability (HKC) explains $6.1 \%$ of the total variance, through working closely with other employees.

Table 4 provides the descriptive statistics and correlation matrix of the key variables. The majority of correlations are statistically significant at $p<0.01$. All of the measures are relatively distinct, with the highest correlation measured at 0.656 and the lowest at 0.245 .

\subsection{Results of implementing and not-implementing KM organizations}

To investigate the influence on organizational knowledge capability and knowledge sharing when $\mathrm{KM}$ is implemented in the firm, this study uses implementation or non-implementation of $\mathrm{KM}$ as a 
Yang \& Chen: Organizational knowledge capabilities

Table 3

Result of exploratory factor analysis

\begin{tabular}{|c|c|c|c|c|}
\hline \multirow[b]{2}{*}{ Items } & \multicolumn{4}{|c|}{ Factor loading } \\
\hline & F1 & $\mathrm{F} 2$ & F3 & $\mathrm{F} 4$ \\
\hline \multicolumn{5}{|c|}{ Technical knowledge capability ( $\alpha=0.8514)$} \\
\hline TKC-1 & 0.885 & & & \\
\hline TKC-2 & 0.863 & & & \\
\hline TKC-3 & 0.788 & & & \\
\hline TKC-4 & 0.709 & & & \\
\hline \multicolumn{5}{|c|}{ Cultural knowledge capability ( $\alpha=0.8611$ ) } \\
\hline CKC-1 & & 0.805 & & \\
\hline CKC-2 & & 0.758 & & \\
\hline CKC-3 & & 0.709 & & \\
\hline CKC-4 & & 0.610 & & \\
\hline \multicolumn{5}{|c|}{ Structural knowledge capability ( $\alpha=0.8215$ ) } \\
\hline SKC-1 & & & 0.815 & \\
\hline SKC-2 & & & 0.717 & \\
\hline SKC-3 & & & 0.678 & \\
\hline SKC-4 & & & 0.645 & \\
\hline \multicolumn{5}{|c|}{ Human knowledge capability ( $\alpha=0.8331$ ) } \\
\hline HKC-1 & & & & 0.847 \\
\hline HKC-2 & & & & 0.788 \\
\hline HKC-3 & & & & 0.701 \\
\hline
\end{tabular}

Extraction method: principal component analysis; rotation method: Varimax with Kaiser normalization.

Table 4

Descriptive statistics and correlation matrix of the key variable

\begin{tabular}{|c|c|c|c|c|c|c|c|}
\hline Variables & Mean & SD & TKC & CKC & SKC & HKC & KS \\
\hline TKC & 5.9580 & 0.8257 & 1.00 & & & & \\
\hline CKC & 5.2217 & 0.9985 & $0.394^{* *}$ & 1.00 & & & \\
\hline SKC & 4.6006 & 1.0737 & $0.318 * *$ & $0.647 * *$ & 1.00 & & \\
\hline HKC & 4.6159 & 1.0156 & $0.245^{* *}$ & $0.656 * *$ & $0.620 * *$ & 1.00 & \\
\hline KS & 5.2686 & 0.8881 & $0.468^{* *}$ & $0.583^{* *}$ & $0.571 * *$ & $0.566 * *$ & 1.00 \\
\hline
\end{tabular}

** Correlation is significant at the 0.01 level.

comparative criterion to test the effects on OKC and KS. Accordingly, we split the sample into two groups: implementing $\mathrm{KM}$ or not. To validate this hypothesis, $t$-tests are used, and the results are shown in Table 5.

It can be seen that the mean contribution score for each variable, except technical capability, is significanlty higher for the group implementing KM than for those not-implementing KM - that is, the implementation of KM enriches the cultural, structural, and human knowledge capabilities; on the other hand, the difference in knowledge sharing is also significant. Apparently, the firms which implement KM invest a lot of effort and money to improve the knowledge flow environment (e.g. collaborative culture, employee intention by incentive and reward, and interpersonal understanding by social networks). Thus, our findings suggest that implementing KM has an effect on organizational knowledge capabilities and knowledge sharing. Thus, Hypothesis 2a is confirmed and Hypothesis $2 \mathrm{~b}$ is partially supported by the data (improvement in technical knowledge capability is not confirmed).

\subsection{Results of regression analysis}

A multiple regression analysis is used to examine the hypotheses and the relationship between organizational knowledge capabilities and knowledge sharing in two independent models. Knowledge 
Yang \& Chen: Organizational knowledge capabilities

Table 5

Result of the $t$-test

\begin{tabular}{|c|c|c|c|c|c|c|}
\hline \multirow[b]{2}{*}{ Variables } & \multicolumn{2}{|c|}{$\begin{array}{l}\text { Implementing KM } \\
\quad(N=131)\end{array}$} & \multicolumn{2}{|c|}{$\begin{array}{c}\text { Not implementing KM } \\
(N=125)\end{array}$} & \multirow[b]{2}{*}{$t$ Value } & \multirow[b]{2}{*}{ Significance } \\
\hline & Mean & SD & Mean & SD & & \\
\hline KS & 5.398 & 0.8247 & 5.133 & 0.9342 & 2.403 & $0.017^{*}$ \\
\hline TKC & 5.891 & 0.8003 & 6.028 & 0.8491 & -1.327 & 0.186 \\
\hline CKC & 5.397 & 0.8671 & 5.038 & 1.0934 & 2.917 & $0.004^{* *}$ \\
\hline SKC & 4.931 & 0.9426 & 4.254 & 1.0966 & 5.307 & $0.000 * * *$ \\
\hline HKC & 4.741 & 0.9201 & 4.485 & 1.0954 & 2.021 & $0.045^{*}$ \\
\hline
\end{tabular}

${ }^{*} p<0.05 ;{ }^{* *} p<0.01 ;{ }^{* *} p<0.001$.

sharing is considered to be a dependent variable, and the independent variables are organizational knowledge capabilities, including technical, cultural, structural, and human knowledge capabilities. The organizational knowledge capabilities are considered as an aggregate variable in model 1 and as four separate variables in model 2 . The organizational knowledge capabilities are significantly related with knowledge sharing $(t=13.209, p<0.001)$, supporting Hypothesis 1 in model 1 . Model 2 demonstrates a more detailed relationship between organizational knowledge capabilities and knowledge sharing. The results for model 2 show that technical, structural, and human knowledge capabilities are likely to drive knowledge sharing activities at a statistically significant level. Hypotheses 1b, 1c, and $1 \mathrm{~d}$ are therefore supported. However, there is no significant association (although the correlation is close to significance) between cultural knowledge capabilities and knowledge sharing; therefore, Hypothesis 1a is not confirmed. Finally, no statistical correlation with knowledge sharing was found for any control variable except education was found. The results are shown in Table 6.

We now examine the same relationship, but separating the sample into the groups implementing KM and not implementing KM. Results from the regression analysis for each group are shown in Table 7. Both achieve statistical significance at $p<0.001$. The result for the group not-implementing KM shows that technical knowledge capabilities $(p<0.001)$ are positively associated with knowledge sharing activities. However, cultural, structural, and human knowledge capabilities are not significantly related to knowledge sharing. These findings suggest that technical knowledge is the capability most frequently useful for enabling employees to share knowledge in a firm which has not implemented KM.

Table 6

Results of regression analysis for knowledge sharing

\begin{tabular}{|c|c|c|c|c|c|c|}
\hline \multirow[b]{2}{*}{ Variables } & \multicolumn{3}{|c|}{ Model $1(N=256)$} & \multicolumn{3}{|c|}{ Model $2(N=256)$} \\
\hline & $\beta$ & $t$-Value & Significance & $\beta$ & $t$-Value & Significance \\
\hline \multicolumn{7}{|c|}{ Independent variables } \\
\hline OKC & 0.645 & 13.209 & $0.000 * * *$ & - & - & - \\
\hline TKC & - & - & - & 0.250 & 5.080 & $0.000 * * *$ \\
\hline CKC & - & - & - & 0.134 & 1.964 & 0.051 \\
\hline SKC & - & - & - & 0.190 & 2.974 & $0.003 * *$ \\
\hline HKC & - & - & - & 0.263 & 4.188 & $0.000 * * *$ \\
\hline \multicolumn{7}{|c|}{ Control variables } \\
\hline Gender & -0.073 & -1.485 & 0.139 & -0.077 & -1.556 & 0.121 \\
\hline Age & 0.035 & 0.693 & 0.489 & 0.049 & 0.972 & 0.332 \\
\hline Education & 0.104 & 2.221 & $0.027^{*}$ & 0.094 & 1.986 & $0.048^{*}$ \\
\hline Firm size & -0.003 & -0.068 & 0.946 & -0.005 & -0.111 & 0.912 \\
\hline$R^{2}$ & \multicolumn{3}{|c|}{0.507} & \multicolumn{3}{|c|}{0.514} \\
\hline$\Delta R^{2}$ & \multicolumn{3}{|c|}{0.497} & \multicolumn{3}{|c|}{0.498} \\
\hline$F$ & \multicolumn{3}{|c|}{$51.404^{* * *}$} & \multicolumn{3}{|c|}{$32.627^{* * *}$} \\
\hline
\end{tabular}

${ }^{*} p<0.05 ;{ }^{*} p<0.01 ;{ }^{* *} p<0.001 ; \beta$ : standardized regression coefficient. 
The result for the group implementing KM indicates that technical knowledge capabilities ( $p<$ $0.001)$, structural knowledge capabilities $(p<0.01)$, and human knowledge capabilities $(p<0.001)$ are positively associated with knowledge sharing activities. Again, no significant correlation with knowledge sharing is found for cultural knowledge capability. Compared to the statistical results for the group not-implementing KM, it can be seen that both emphasize the importance of technical knowledge capability, but human and structural knowledge capabilities have a stronger association with knowledge sharing activities in the firms which have already implemented KM. Following this concept, we conclude that people and organizational structure, not technology, are the priority for developing organizational capability in a knowledge business. Finally, no statistical correlation of the control variables to knowledge sharing is found, except for education and firm size (when firms implement KM).

\section{Discussion}

The main objective of this study is to investigate the relationship between organizational knowledge capabilities and knowledge sharing within a firm. The findings show how organizational knowledge capabilities improve the context of knowledge sharing and facilitate the behaviors of knowledge sharing. Based on these results, some interesting propositions are exhibited.

\subsection{The effects for a firm implementing $K M$}

The most important concern in KM is to acquire strategic advantages by using knowledge effectively. Therefore, KM tends to develop organizational capabilities for achieving effective knowledge sharing. This study reveals that firms performing a KM Program show improved organizational knowledge capabilities and knowledge sharing. The differences are most significant for structural knowledge capability, with cultural knowledge capability second. This shows that businesses conduct greater effort and invest more money to improve organizational structure (i.e. encourage the sharing of knowledge by an incentive system) and organizational culture (i.e. establish friendly and collaborative surroundings) when they implement KM.

In contrast, technical knowledge capability does not improve when implementing KM in a business, but its mean score is higher than other knowledge capabilities - that is, technical knowledge capability is a feature of firms possessing mutual skills, which are easy to form and accumulate within organizations. Following the development of information technology, many firms have already established IT-based systems to support business activities and IT acceptance has improved increasingly in the past decade. Therefore, technical knowledge capability is a fundamental necessary skill, not a sufficient condition, in a knowledge organization.

Table 7

Results of regression analysis (implementing KM or not)

\begin{tabular}{|c|c|c|c|c|c|c|}
\hline \multirow[b]{2}{*}{ Independent variable } & \multicolumn{3}{|c|}{ Not-implementing KM $(N=125)$} & \multicolumn{3}{|c|}{ Implementing KM $(N=131)$} \\
\hline & $\beta$ & $t$-Value & Significance & $\beta$ & $t$-Value & Significance \\
\hline TKC & 0.295 & 3.700 & $0.000 * * *$ & 0.253 & 3.975 & $0.000 * * *$ \\
\hline CKC & 0.153 & 1.401 & 0.164 & 0.155 & 1.972 & 0.051 \\
\hline SKC & 0.108 & 1.078 & 0.283 & 0.207 & 2.793 & $0.006^{* *}$ \\
\hline HKC & 0.177 & 1.770 & 0.079 & 0.375 & 5.042 & $0.000 * * *$ \\
\hline Gender & -0.035 & -0.406 & 0.685 & -0.087 & -1.596 & 0.113 \\
\hline Age & 0.115 & 1.272 & 0.206 & -0.025 & -0.438 & 0.662 \\
\hline Education & 0.018 & 0.227 & 0.820 & 0.188 & 3.404 & $0.001 * *$ \\
\hline Firm size & 0.073 & 1.000 & 0.319 & -0.115 & -1.993 & $0.048^{*}$ \\
\hline$R^{2}$ & \multicolumn{3}{|c|}{0.428} & \multicolumn{3}{|c|}{0.663} \\
\hline$\Delta R^{2}$ & \multicolumn{3}{|c|}{0.389} & \multicolumn{3}{|c|}{0.641} \\
\hline$F$ & \multicolumn{3}{|c|}{$10.868^{* * *}$} & \multicolumn{3}{|c|}{$30.011^{* * *}$} \\
\hline
\end{tabular}

${ }^{*} p<0.05 ;{ }^{* *} p<0.01 ;{ }^{* *} p<0.001 ; \beta$ : standardized regression coefficient. 
Yang \& Chen: Organizational knowledge capabilities

\subsection{The relationship between $O K C$ and $K S$}

Since knowledge sharing is a challenging task, the results of this study suggest fostering this behavior or activity through the enhancement of organizational knowledge capabilities. If an organization possesses more organizational capabilities for combining knowledge resources so as to generate new capabilities, then knowledge sharing is likely to be more effective. Our results show that technical, structural, and human knowledge capabilities all exert significant influences on knowledge sharing activities. Information and communication technology (e.g. e-mail, on-line forums, or search engines) are important and well-known resources for organizational knowledge sharing; however, technical knowledge and capabilities are more essential than information technology itself.

Technical knowledge capability emphasizes knowledge integration in an organization through the capability that the information infrastructure provides for knowledge sharing - that is, the more technical knowledge organizations own, the more their members tend to share knowledge. In addition, structural knowledge capability emphasizes the development of a mechanism including organizational regulation and an incentive system. Reward, compensation, promotion, and prizes are among the incentive systems which can encourage individuals to contribute their professional knowledge to the organization. The organizational regulation is composed of a subjective norm, political directives, and a procedure design that are common ordinances to foster knowledge sharing behavior within the firm's members. A good structural knowledge capability increases the individual's motivation for knowledge sharing. Beyond identified effects, human knowledge capability concentrates on establishing positive relationships and a good social network for effective knowledge sharing. Quality relationships can improve the trust among a firm's members and further promote the members' attitude to and intention of knowledge sharing in an organization.

Cultural knowledge capability has a non-significant influence on knowledge sharing behaviors, which is contradictory to the proposed hypothesis. Three possible reasons for this are suggested. First, culture is an intangible resource in an organization, which can affect many organizational activities (e.g. organizational learning, marketing strategy, or decision making), but is difficult to form, cultivate, and measure. Although cultural knowledge capability stresses the support provided by a collaborative atmosphere, it is unable to help in establishing such an organizational culture. In other words, cultural knowledge capability has a non-significant effect on business culture, and thus on knowledge sharing. Second, culture could be an indirect factor, which drives knowledge sharing by means of other resources or capabilities. For example, some researchers propose that a knowledge sharing culture is affected by organizational commitment and the context of social interaction [50]. Bock et al. [12] demonstrated that an organizational climate has both a direct effect and an indirect effect (mediated by a subjective norm) on knowledge sharing. Third, 'culture' covers a wide range of concepts. This study uses building up organizational collaborative contexts and valuing organizational knowledge as the measurements of cultural knowledge capability. Although the content validity of this variable is acceptable, it might not be suitable to the issue of knowledge sharing considered here. It is possible that societal culture might affect knowledge sharing behavior; i.e. the tendency of knowledge sharing in East Asian and Western societies is different [18, 51]. The respondents of this study are native to and educated in Taiwan, and further exploration in other countries is suggested as the results might prove to be different. A positive relationship between cultural knowledge and knowledge sharing is not supported by our results. Advanced research to test for a more complex connection between cultural capability and knowledge sharing is a path for future work.

\subsection{Comparative relationship between $O K C$ and $K S$ while implementing $K M$}

Despite organizational knowledge capability having demonstrated its influence on knowledge sharing, another interesting theme is presented in this study. After exploring the various capabilities to affect knowledge sharing from different groups, implementing KM and not implementing KM, divergent results are shown. Summarizing significant findings for the business of whether or not to implement KM, we conclude that firms not-implementing KM focus on technical knowledge capabilities while firms implementing KM target technical, structural, and human knowledge capabilities. A 
Yang \& Chen: Organizational knowledge capabilities

firm's members mainly use internet-based resources and capabilities to access and contribute their knowledge so as to achieve the best possible effectiveness of knowledge sharing if their organization has not undertaken a KM program. Obviously, knowledge in firms not-implementing KM is elicited through IT and technical knowledge capability. On the other hand, firms which implement KM shift their capabilities to structural and human knowledge, enriching the sharing behavior. One reasonable explanation is that social capital consisting of structural, cognitive, and relational capital is more complicated than information technology; as noted by O'Dell et al. [4], behavioral and cultural changes are a bigger challenge than new IT tools. The capabilities and network relationships of social capital have a positive effect on knowledge movement and knowledge sharing [45], and in particular on tacit knowledge flow [23]. Examining the interactive effects between social capital dimensions may prove an interesting path for further study.

\section{Conclusion}

A knowledge organization focuses on developing interpersonal, structural, and network relationships to achieve effective knowledge sharing and to further generate new knowledge or capabilities for organizational competitiveness and success. This paper elaborates upon some capability variables which can affect knowledge sharing behavior. By identifying these capability factors as the determinants of shared knowledge, organizations can more efficiently deploy and organize their resources and capabilities for knowledge sharing. This study focuses on the investigation of intraorganizational capabilities and sharing behaviors, and future research can be conducted on the activities of extra-organization sharing or multinational corporations.

\section{Acknowledgements}

This research was partially sponsored by the National Science Council (NSC) of Taiwan (93-2416-H009-012).

\section{References}

[1] M. Shin, A framework for evaluating economics of knowledge management systems, Information and Management 42(1) (2004) 176-196.

[2] W.R. King, P.V. Marks and S. McCoy, The most important issues in knowledge management, Communications of the ACM 45(9) (2002) 93-97.

[3] P.H.J. Hendriks, Why share knowledge? The influence of ICT on the motivation for knowledge sharing, Knowledge and Process Management 6(2) (1999) 91-100.

[4] C. O’Dell, K. Wiig and P. Odem, Benchmarking unveils emerging knowledge management strategies, Benchmarking 6(3) (1999) 202-211.

[5] G. Widen-Wulff and M. Ginman, Explaining knowledge sharing in organizations through the dimensions of social capital, Journal of Information Science 30(5) (2004) 448-458.

[6] W. Scholl, C. König, B. Meyer, and P. Heisig, The future of knowledge management: an international delphi study, Journal of Knowledge Management 8(2) (2004) 19-35.

[7] T.H. Davenport and L. Prusak, Working Knowledge: how Organizations Manage what they Know (Harvard Business School Press, Boston, MA, 1998).

[8] G. Szulanski, Exploring internal stickiness: impediments to the transfer of best practices within the firm, Strategic Management Journal 17(Winter Special Issue) (1996) 27-44.

[9] M.M. Wasko and S. Faraj, Why should I share? Examining social capital and knowledge contribution in electronic networks of practice, MIS Quarterly 29(1) (2005) 35-58.

[10] J.L. Cummings and B.S. Teng, Transferring R\&D knowledge: the key factors affecting knowledge transfer success, Journal of Engineering Technology Management 20(1-2) (2003) 39-68.

[11] M. Alavi and D.E. Leidner, Review: knowledge management and knowledge management systems: conceptual foundations and research issues, MIS Quarterly 25(1) (2001) 107-136. 
Yang \& Chen: Organizational knowledge capabilities

[12] G.W. Bock, R.W. Zmud, Y.G. Kim and J.N. Lee, Behavioral intention formation in knowledge sharing: examining the roles of extrinsic motivators, social-psychological forces, and organizational climate, MIS Quarterly 29(1) (2005) 87-111.

[13] S. Ryu, S.H. Ho and I.Han, Knowledge sharing behavior of physicians in hospitals, Expert Systems with Application 25 (2003) 113-122.

[14] H.F. Lin and G.G. Lee, Perceptions of senior managers toward knowledge-sharing behavior, Management Decision 42(1) (2004) 108-125.

[15] J.H. Dyer and K. Nobeoka, Creating and managing a high-performance knowledge-sharing network: the Toyota case, Strategic Management Journal 21(3) (2000) 345-367.

[16] R. McDermott and C. O'Dell, Overcoming cultural barriers to sharing knowledge, Journal of Knowledge Management 5(1) (2001) 76-85.

[17] V. Albino, A.C. Garavelli and G. Schiuma, Knowledge transfer and inter-firm relationships in industrial districts: the role of the leader firm, Technovation 19(1) (1999) 53-63.

[18] C.K. Lee and Suliman A. Factors impacting knowledge sharing, Journal of Information \& Knowledge Management 1(1) (2002) 49-56.

[19] J.N. Lee, The impact of knowledge sharing, organizational capability and partnership quality on IS outsourcing success, Information and Management 38(5) (2001) 323-335.

[20] R. Ruggles, The state of the notion: knowledge management in practice, California Management Review 40(3) (1998) 80-89.

[21] H. Lee and B. Choi, Knowledge management enablers, processes, and organizational performance: an integrative view and empirical examination, Journal of Management Information Systems 20(1) (2003) 179-228.

[22] S.L. Pan and H. Scarbrough, A socio-technical view of knowledge-sharing at Buckman Laboratories, Journal of Knowledge Management 2(1) (1998) 55-66.

[23] R.K. Lahti and M.M. Beyerlein, Knowledge transfer and management consulting: a look at the firm, Business Horizons 43(1) (2000) 65-74.

[24] S.O.S. Syed-Ikhsan and F. Rowland, Knowledge management in a public organization: a study on the relationship between organizational elements and the performance of knowledge transfer, Journal of Knowledge Management 8(2) (2004) 95-111.

[25] S.C. Goh, Managing effective knowledge transfer: an integrative framework and some practice implications, Journal of Knowledge Management 6(1) (2002) 23-30.

[26] B.D. Janz and P. Prasarnphanich, Understanding the antecedents of effective knowledge management: the importance of a knowledge-centered culture, Decision Sciences 34(2) (2003) 351-384.

[27] M. Gibbert, S. Jenzowsky, C. Jonczky, M. Thiel and S. Volpel, ShareNet - the next generation knowledge management. In: T.H. Davenport, M. Gilbbert and J.B. Probst (eds), Knowledge management case book: Siemens best practises (Wiley, 2002).

[28] H. Hall, Input-friendliness: motivating knowledge sharing across intranets, Journal of Information Science 27(3) (2001) 139-146.

[29] D.G. Ko, L.J. Kirsch and W.R. King, Antecedents of knowledge transfer from consultants to clients in enterprise system implementations, MIS Quarterly 29(1) (2005) 59-86.

[30] W. Tsai, Social structure of "coopetition" within a multiunit organization: coordination, competition, and intraorganizational knowledge sharing, Organization Science 13(2) (2002) 179-190.

[31] E. Bolisani and E. Scarso, Information technology management: a knowledge based perspective, Technovation 19(4) (1999) 209-217.

[32] A. Malhotra and A. Majchrzak, Enabling knowledge creation in far-flung teams: best practices for IT support and knowledge sharing, Journal of Knowledge Management 8(4) (2004) 75-88.

[33] P. Gorman and H. Thomas, The theory and practice of competence-based competition, Long Range Planning 30(4) (1997) 615-620.

[34] S. Dutta, O. Narasimhan and S. Rajiv, Conceptualizing and measuring capabilities: methodology and empirical application, Strategic Management Journal 26 (2005) 277-285.

[35] R.M. Grant, Toward a knowledge-based theory of the firm, Strategic Management Journal 17(Winter Special Issue) (1996) 109-122.

[36] A.H. Gold, A. Malhotra and A.H. Segars, Knowledge management: an organizational capabilities perspective, Journal of Management Information Systems 18(1) (2001) 185-214.

[37] R. Dawson, Knowledge capabilities as the focus of organisational development and strategy, Journal of Knowledge Management 4(4) (2000) 320-327(8).

[38] E. Coakes, Knowledge management: a sociotechnical perspective. In: E. Coakes et al. (eds), Knowledge Management in the Sociotechnical World (Springer, 2002). 
Yang \& Chen: Organizational knowledge capabilities

[39] S.H. Chuang, A resource-based perspective on knowledge management capability and competitive advantage: an empirical investigation, Expert Systems with Applications 27(3) (2004) 459-465.

[40] L.P. Donoghue, J.G. Harris and B.E. Weitzman, Knowledge management strategies that create value, Andersen Consulting's Outlook Journal 1 (1999) 48-53.

[41] K.M. Wiig, Knowledge Management (Schema Press, Texas, 1994).

[42] D.W. De Long and L. Fahey, Diagnosing cultural barriers to knowledge management, Academy of Management Executive 14(4) (2000) 113-127.

[43] J.T. Yang and C.S. Wan, Advancing organizational effectiveness and knowledge management implementation, Tourism Management 25(5) (2004) 593-601.

[44] S. Gopalakrishnan and M. Santoro, Distinguishing between knowledge transfer and technology transfer activities: the role of key organizational factors, IEEE Transactions on Engineering Management 51(1) (2004) 57-69.

[45] V. Albino, A.C. Garavelli and M. Gorgoglione, Organization and technology in knowledge transfer, Benchmarking 11(6) (2004) 584-600.

[46] A.S. Bharadwaj, A resource-based perspective on information technology capability and firm performance: an empirical investigation, MIS Quarterly 24(1) (2000) 169-195.

[47] T. Kalling, Knowledge management and the occasional links with performance, Journal of Knowledge Management 7(3) (2003) 67-81.

[48] M. Khalifa, R. Lam and M. Lee, Determinants of successful knowledge management programs, Electronic Journal on Knowledge Management 1(2) (2003) 103-112.

[49] J. Cummings, Work groups, structural diversity, and knowledge sharing in a global organization, Management Science 50(3) (2004) 352-364.

[50] C.E. Connelly and E.K. Kelloway, Predictors of employees' perceptions of knowledge sharing cultures, Leadership \& Organization Development Journal 24(5/6) (2003) 294-301.

[51] K. Möller and S. Svahn, Crossing east-west boundaries. Knowledge sharing in intercultural business networks, Industrial Marketing Management 3 (2004) 219-228.

\section{Appendix}

Table A1

The profile of respondents

\begin{tabular}{lllll}
\hline Measure & Items & Frequency & Percentage (\%) & Cumulative (\%)
\end{tabular}

(a) Industry type

Government

Finance/insurance

Semiconductor/opto-electronics

Communication/network

Computer

Service

Manufacturing

Others

(b) Demographic information of respondents

Gender

Age

Firm size

Education

\begin{tabular}{lrcc} 
Male & 153 & 59.8 & 59.8 \\
Female & 103 & 40.2 & 100 \\
$\leq 30$ & 91 & 35.5 & 35.5 \\
$31-40$ & 80 & 31.3 & 66.8 \\
$>40$ & 85 & 33.2 & 100 \\
$\leq 1000$ & 123 & 48.0 & 48.0 \\
$>1000$ & 133 & 52.0 & 100 \\
M.S. or Ph.D. degree & 67 & 26.2 & 26.2 \\
Bachelor's degree & 182 & 71.1 & 97.3 \\
Others & 7 & 2.7 & 100 \\
\hline
\end{tabular}


Yang \& Chen: Organizational knowledge capabilities

Table A1 (continued)

\begin{tabular}{|c|c|c|c|c|}
\hline Measure & Items & Frequency & Percentage (\%) & Cumulative (\%) \\
\hline \multirow[t]{7}{*}{ Department } & Headquarters & 48 & 18.8 & 18.8 \\
\hline & Marketing & 34 & 13.3 & 32.1 \\
\hline & Manufacturing & 10 & 3.9 & 36.0 \\
\hline & $\mathrm{R} \& \mathrm{D}$ & 43 & 16.8 & 52.8 \\
\hline & Accounting & 30 & 11.7 & 64.5 \\
\hline & MIS & 37 & 14.5 & 79.0 \\
\hline & Others & 54 & 21.0 & 100 \\
\hline \multirow[t]{5}{*}{ Position } & Superintendent & 51 & 19.9 & 19.9 \\
\hline & Department manager & 29 & 11.3 & 31.2 \\
\hline & Middle level manager & 46 & 18.0 & 49.2 \\
\hline & Employees & 126 & 49.2 & 98.4 \\
\hline & Others & 4 & 1.6 & 100 \\
\hline
\end{tabular}

Table A2

Questionnaire items

Factors and items descriptions

Organizational knowledge capability [36, 39]

Cultural knowledge capability

Organizational employees are valued for their individual expertise.

Organizational employees understand the importance of knowledge.

Organizational employees are encouraged to interact with other groups.

The benefits of sharing knowledge outweigh the costs.

Structural knowledge capability

Our organization has a reward system for sharing knowledge.

Our organization structure facilitates the discovery of new knowledge.

Our organization structure facilitates the creation of new knowledge.

Our organization facilitates knowledge exchange across functional boundaries.

Human knowledge capability

Organizational employees can make suggestions about others' tasks.

Organizational employees can communicate not only with member of their own department, but also with members of other departments.

Organizational employees can understand not only their own tasks, but also others' tasks.

Technical knowledge capability

Organizational employees use technology to search for new knowledge.

Organizational employees use technology to retrieve knowledge about its products and processes.

Organizational employees use technology to retrieve knowledge about markets and competition.

Organizational employees use technology to cooperate with a fellow employee.

\section{Knowledge sharing $[12,19]$}

Organizational employees share business proposals and reports with each other.

Organizational employees share business manuals, models, and methodologies with each other.

Organizational employees share each other's success and failure stories.

Organizational employees share business knowledge gained from news, magazines, and journals.

Organizational employees share know-how from work experiences with each other.

Organizational employees share each other's know-where and know-whom.

Organizational employees share expertise obtained from education and training. 